\title{
O SPORT EM TRANSIÇÃO: RIO DE JANEIRO,
}

\section{1-1868}

SPORT IN TRANSITION: RIO DE JANEIRO, 1851-1868

EL DEPORTE EN TRANSICIÓN: RIO DE JANEIRO, 1851-1868

\section{Victor Melo*}

\section{Palavras-chave}

História. Esportes.

Turfe. Remo.
Resumo: Este estudo tem por objetivo discutir as experiências esportivas em curso no Rio de Janeiro entre os anos de 1851, momento em que já tinham sido fundados os dois primeiros clubes, e 1868, quando foi criada uma agremiação mais sólida e longeva, 0 Jockey Club. Para alcance do objetivo, como fontes foram utilizados periódicos editados na cidade no período em tela. Ao final, concluímos que a conjugação de aspectos internos do campo esportivo com fatores externos/contextuais ajuda a entender o porquê de o esporte somente dar passos mais seguros na capital brasileira a partir do final dos anos 1860 .

\section{Keywords:}

History. Sports. Turf. Rowing.

Palabras clave Historia. Deportes. Turf. Remo.
Abstract: This study discusses sporting experiences under way in Rio de Janeiro between 1851, when the first two clubs had been already founded, and 1868, when a key and long-lasting association was created - the Jockey Club. To reach that aim, newspapers and magazines published in the city in the period under consideration were used as sources. Finally, we concluded that the combination of internal aspects of the sports field with external/contextual factors helps to understand why sport only developed in the Brazilian capital in the late 1860s.

Resumen: Este estudio tiene como objetivo discutir las experiencias deportivas en marcha en Rio de Janeiro entre los años 1851, cuando habían sido fundados los dos primeros clubes, y 1868, cuando fue creada una asociación más sólida y longeva, el Jockey Club. Para alcanzar el objetivo, se utilizaron como fuentes periódicos publicados en la ciudad en ese período. Al final, concluimos que la combinación de aspectos internos del campo deportivo con factores externos/contextuales ayuda a entender la razón de que el deporte haya dado pasos más seguros en la capital del país solamente a partir de fines de la década de 1860 .
*Universidade Federal do Rio de Janeiro. Rio de Janeiro, RJ, Brasil. E-mail: victor.a.melo@uol.com.br

Recebido em: 09-08-2014 Aprovado em: 08-12-2014 (c) (i) () Licence 


\section{INTRODUÇÃO}

Nos anos de 1849 e 1851 foram criadas as duas pioneiras agremiações esportivas do Rio de Janeiro, provavelmente do Brasil, o Club de Corridas, dedicado ao turfe, e a Sociedade Recreio Marítimo, ligada ao remo. Mesmo enfrentando dificuldades, inclusive no que tange à organização de seus primeiros eventos, pode-se dizer que estabeleceram muitos dos elementos constituintes de um campo esportivo ${ }^{1}$ que somente tornar-se-ia melhor delineado a partir da transição das décadas de 1860/1870 (MELO, 2014).

Entre 1851 e 1868 percebe-se um período de transição na conformação do fenômeno esportivo na capital do Império. Alguns indícios desse processo podem mesmo ser notáveis no âmbito da terminologia. Se, na primeira metade do século XIX, as palavras athleta e sport começaram a circular pela cidade, tanto nos periódicos quanto nos dicionários (MELO, 2014), nas décadas de 1850 e 1860 a utilização dos termos tornou-se mais usual. Além disso, 0 sentido mobilizado aproximou-se do que seria consagrado quando o campo definitivamente se consolidasse.

O termo athleta vinha sendo mais utilizado metaforicamente como sinônimo de "lutador". Esse uso continuava muito comum nos periódicos, especialmente para se referir àqueles que de alguma forma desafiavam ou enfrentavam os poderes constituídos, não poucas vezes envolvidos em polêmicas públicas. Era, por exemplo, usado para definir as ações de alguns periódicos como $O$ Grito Nacional, que se dedicava a criticar o tráfico negreiro e a permanência da escravidão (1852, p. 1). Em 1856, aliás, foi lançado O Athleta, um jornal muito combativo e polêmico, cuja atuação chegou a desencadear um debate sobre a liberdade de imprensa ${ }^{2}$.

Havia, contudo, uma novidade no tocante ao uso do termo: ele passa também a ser mais comumente utilizado para designar os que participavam de lutas realizadas em casas de espetáculo. Esse foi o caso de Mr. Charles, o athleta que, na segunda metade dos anos 1850, no circo da Rua da Guarda Velha, desafiava outros lutadores, entusiasmando a assistência com sua performance. Prometia pagar um conto de réis para quem o vencesse, seguindo as regras publicadas nos jornais (DIÁRIO... 1856b, p. 4).

Tornou-se mesmo mais comum o uso do termo relacionado a valências físicas. Isso era bem perceptível em espetáculos circenses, que desde a primeira metade do século XIX logravam grande sucesso, tendo a ginástica como uma das principais atrações (MELO; PERES, 2014). Indivíduos fortes, musculosos, corpulentos passaram a ser chamados usualmente de "athletas". Esse foi o caso de Achille Giorgini, o "artista athletico", diretor de uma companhia que se apresentou nos palcos do Rio de Janeiro. Sua especialidade era a execução de "exercícios hercúleos na coluna olímpica" (DIÁRIO..., 13 jul. 1855, p. 4).

Merece também destaque que pelo menos um colégio informou em sua publicidade que oferecia a seus alunos "jogos athleticos": o Instituto Colegial (ALMANAK..., 1854, p. 344)3. Localizada em Nova Friburgo, era uma das mais importantes e mais avançadas escolas brasileiras dos meados do século XIX. A mobilização do termo por uma instituição educacional é mais um interessante indicador de como sua utilização se difundia e mudava de perfil.

1 Estamos aqui trabalhando com a ideia de campo esportivo conforme sugerida por Bourdieu (1983). 2 Sobre a polêmica, ver: Correio Mercantil, 1856b, p. 1. 
Já o termo sport, como ocorria anteriormente, seguiu sendo identificado como um típico hábito de britânicos, considerado um contributo para que se desenvolvesse a personalidade dos líderes nacionais. Da mesma forma, começaram a circular mais notícias sobre os novos hábitos sportivos dos franceses, dando conta do sucesso das atividades turfísticas (ver, por exemplo, DIÁRIO..., 1857, p. 2). De fato, um dos argumentos que mais sustentou a defesa do desenvolvimento da prática no Brasil foi exatamente ser valorizada em países civilizados, fato encarado como sinal de adesão a ideias de progresso.

Considerando a necessidade de melhor compreender esse período de transição na conformação do fenômeno no Rio de Janeiro do século XIX, não somente por ser importante para entender a estruturação do campo esportivo, como também para que se possa lançar luz sobre a relação do esporte com o contexto histórico, este estudo tem por objetivo discutir as experiências esportivas em curso na cidade entre os anos de 1851, momento em que estavam fundados os dois primeiros clubes, e 1868, quando foi criada uma agremiação mais sólida e longeva, o Jockey Club.

Para alcance do objetivo, foram utilizados como fontes periódicos editados na cidade no período em tela, consultados na Hemeroteca Digital Brasileira e na Biblioteca Nacional. Para análise e interpretação do material, tivemos em conta as sugestões de Tania Regina de Luca (2005), considerando o que foi publicado como representações entabuladas a partir de determinado ponto de vista. Vale considerar que uma parte do material usado se trata de anúncios dos próprios clubes ou notas muito sumárias sobre os eventos. Quando necessário, na medida em que julgamos ter algum potencial de esclarecimento, fizemos referência à peculiaridade do jornal/revista e do autor.

Ainda que já existam alguns estudos sobre o esporte no Rio de Janeiro do século XIX - como os de Mascarenhas (1999), Melo (2001), Lucena (2001) e Schetino (2008) -, nenhum desses se debruçou mais profundamente sobre os primeiros momentos da constituição do campo esportivo, excluindo-se o de Melo (2014), que abordou as experiências esportivas na primeira metade da centúria. A originalidade deste artigo é, portanto, ao descortinar e fazer uso de fontes ainda inéditas ou pouco mobilizadas, chamar a atenção para as peculiaridades desse período inicial, apontando olhares sobre o fenômeno que podem ser considerados em futuras investigações.

\section{NOVAS EXPERIÊNCIAS ESPORTIVAS (1851-1856)}

A despeito de as corridas de cavalos já existirem na capital desde a década de 1810 e do grande empenho dos envolvidos com a criação do Club de Corridas (1849), essa pioneira experiência não teve grande êxito. Era complexo gerenciar as competições hípicas, inclusive do ponto de vista financeiro.

Depois da atividade inaugural, realizada em novembro de 1850, novos páreos somente voltaram a ser promovidos no ano seguinte, quando assumiu o negócio João Guilherme Suckow, prussiano que chegara ao Brasil em 1824, integrando tropas a serviço do Império, e se envolvera com a criação de empresas de transporte público e de leilões de animais. Era também fazendeiro e criador de cavalos. Em assembleia realizada em fevereiro de 1851, a 
direção do Club de Corridas ${ }^{4}$ arrendou, para ele e David Stevenson ${ }^{5}$, o Prado Fluminense, hipódromo localizado no bairro do Engenho Novo.

Suckow era um típico empreendedor. Sua relação com o turfe, ainda que a modalidade estivesse ligada a seu ramo de negócios, não se dava somente por interesses financeiros diretos, mas também pelo que lhe permitia angariar de status e distinção. Tal envolvimento o tornara mais reconhecido na cidade: "A tenacidade do Sr. Major Suckow acabará por fazer aclimar entre nós um divertimento hoje admitido e altamente protegido na Europa como utilíssimo para o aperfeiçoamento da raça cavalar" (CORREIO MERCANTIL, 1853, p. 1) ${ }^{6}$.

A sua mentalidade empresarial foi fundamental para a melhor estruturação do esporte, garantindo um primeiro momento de popularidade ${ }^{7}$. De imediato realizou uma série de benefícios no hipódromo e promoveu, já em junho de 1851, sua reinauguração. Logo as corridas de cavalos voltariam a se fazer presentes não somente no Prado, mas também no cotidiano da cidade, um sinal de que se tornavam mais reconhecidas. Gestou-se até mesmo um mercado ao seu redor. Surgiram, por exemplo, as primeiras referências ao turfe no que tange às vestimentas e à venda de produtos em geral, até mesmo brinquedos, como os bonecos "corridas de cavalos", oferecidos pela "Ao paraíso das crianças", notória loja que se localizava na Praça da Constituição (DIÁRIO..., 1858a, p. 2). No Depósito de Perfumarias Inglesas se encontrava o extrato para lenços Jockey Club (CORREIO MERCANTIL, 1856a, p. 4). Aliás, a fantasia de jóquei foi uma das que integrou o préstito carnavalesco de 1855 (CORREIO MERCANTIL, 1855a, p. 2).

Até 1854, seguiu-se com frequência a realização de corridas de cavalos. Nesse ano, um grupo de amadores se organizou para promover eventos de caráter restrito e limitado, contando somente com convidados no público e gentlemen-riders como condutores ${ }^{8}$. Dessa experiência surgiu uma nova agremiação, o Jockey Club Fluminense.

Essa iniciativa não logrou continuidade. A agremiação só promoveu um evento, até porque, no mesmo ano de 1854, um incêndio destruiu o prado, interrompendo as atividades turfísticas na cidade. Suckow já acumulava grande prejuízo e via poucas possibilidades de dar sequência com sucesso ao negócio.

O fato é que, ao contrário da empolgação que tomara conta da cidade nos primeiros anos da década, na segunda metade dos 1850 grassava uma sensação de desânimo. Em 1856, um cronista observou: "Fala-se já muito em regatas, porém ainda nenhuma palavra ouvimos a respeito do prado, que sempre foi costume abrirem-se em junho ou julho, Que faz a sociedade Jockey Club Fluminense? Pretenderá deixar-nos este ano sem corridas?" (DIÁRIO DO RIO DE JANEIRO, 1856a, p. 1) .

\footnotetext{
4 Integravam a diretoria importantes personagens da Corte, como João Pereira Darrigue Faro (visconde do Rio Bonito) e Mariano Procópio Ferreira Lage, ambos ligados à modernização da economia nacional.

5 Stevenson era um advogado britânico que trabalhava para os ingleses no Brasil estabelecidos, notadamente para os que atuavam no comércio e para os envolvidos com a restrição ao tráfico negreiro. Vivia no país desde os anos 1820, agindo também como representante comercial.

6 Esse periódico ocupou espaço de importância no Segundo Reinado. Tinha um perfil político liberal e engajado, ao contrário do mais moderado Jornal do Comércio. A seção na qual foi publicada a notícia, Pacotilha, era escrita por Manuel Antônio de Almeida, cuja obra mais conhecida é Memórias de um Sargento de Milícias. Nesse espaço, eram comentados os principais acontecimentos da cidade.

7 Para mais informações, ver Melo (2013).

8 Os gentlemen-riders não recebiam remuneração ou prêmios para conduzir os cavalos.

9 Esse periódico foi um dos primeiros do país a circular diariamente, caracterizando-se tanto pela ênfase no comercial e na publicidade quanto por adotar uma linha editorial que defendia o progresso do país. Notabilizou-se pelo olhar atento que lançou sobre as mudanças na sociedade da Corte. O responsável pela coluna Folhetim: Conversa com meus Leitores era José de Alencar, que assinou como Al.
} 
A trajetória do remo tem similaridades com a do turfe naquela primeira metade da década de 1850. Em novembro de 1851, a Sociedade Recreio Marítimo promoveu, com grande sucesso, sua primeira atividade (MELO, 2014). Mesmo os que tinham alguma forma de crítica à modalidade não deixaram de reconhecer a relevância que ocuparam as regatas na cidade na ocasião.

Todavia, um novo evento náutico somente ocorreu em 1852, sendo a agremiação já identificada como Sociedade Regata (CORREIO MERCANTIL, 1852a, p. 3). Possivelmente houve uma mudança de nome do antigo clube por ocasião da confecção dos estatutos (CORREIO MERCANTIL, 1852b, p. 2). Os dirigentes, aliás, ao anunciarem que as regatas seriam realizadas em $1^{\circ}$ de novembro, na enseada de Botafogo, aproveitaram para pedir aos sócios a regularização do pagamento das mensalidades, para que os ingressos fossem enviados prontamente. Isto é, embora os páreos fossem programados para um espaço público, previa-se um lugar exclusivo para os associados os acompanharem ${ }^{10}$.

Com o anúncio, surgiu um conflito entre os "pradistas" e os "regatistas" (CORREIO MERCANTIL, 1852c, p. 2). O problema foi que, anteriormente, para o mesmo dia previra-se a realização de corridas de cavalos. A decisão da agremiação náutica causou perplexidade, soando para alguns como uma desnecessária divisão de esforços. Seria difícil para o público comparecer às duas atividades, até porque aconteceriam em lugares distantes, levando-se em conta a dificuldade de transporte, cerca de 10 quilômetros.

Frente à sugestão de que o grupo náutico modificasse a data de sua atividade, um anônimo que assinou como "Remador", embora afirmasse que "a diretoria da Regata deseja toda a prosperidade do recreio das corridas de cavalos, que muito útil é ao país" (CORREIO MERCANTIL, 1852b, p. 1), informou que não seria acatada a solicitação por ser uma imposição estatutária fazer 0 evento em $1^{\circ}$ de novembro. 0 debate foi intenso.

Ao fim, o diretor do Prado Fluminense comunicou a transferência das corridas de cavalos para o dia 7 de novembro, em função da má qualidade da estrada até o hipódromo (CORREIO MERCANTIL, 30 out. 1852e, p. 2). De fato, fora uma semana muito chuvosa, mas, aparentemente, tratou-se de uma saída elegante. Suckow não queria disputar o público com as regatas.

A confusão, contudo, não se encerrou. A Sociedade Regata, a despeito de ter insistido na data e publicado uma série de comunicados nos jornais, realizou um evento restrito aos sócios, longe do litoral e do alcance do grande público, obliterando a visão da assistência por uma linha de embarcações nas quais se encontravam somente os que tinham convites.

Essa postura foi muito criticada e abalou a credibilidade da nova agremiação. A má repercussão foi generalizada, praticamente todos os periódicos da cidade, por semanas, abordaram o fato. Em sinal de desagravo, alguns capitães de navios de guerra organizaram, no mesmo mês, uma nova regata (PERIÓDICO...., 1852, p. 5). 0 evento foi promovido numa região mais central da Baía de Guanabara, em frente à barca de banhos, localizada na altura do Hotel Pharoux (JORNAL DAS SENHORAS, 1852, p. 159), o que facilitou o comparecimento do público, que assistiu com entusiasmo às provas que foram disputadas exclusivamente por militares (JORNAL DO COMÉRCIO, 1852, p. 1).

10 A composição da direção da Sociedade Regata, uma parte que já atuava na Sociedade Recreio Marítimo, nos informa de seu perfil: Joaquim Marques Lisboa, futuro Almirante Tamandaré (presidente); o barão de São Nicolau, Leopoldo Augusto da Camara Lima (vice-presidente); Francisco Leão Cohn, filho de negociante francês, militar de destacada carreira, funcionário da Alfândega (secretário); o comendador Antonio José da Costa Ferreira (tesoureiro). 
Nova regata somente foi realizada em 1853 , dessa vez tendo como lugar a enseada do Caju (DIÁRIO..., 1853, p. 2). Como de costume, um bom público esteve presente. A repercussão foi muito positiva, ainda que persistissem algumas críticas à organização, inclusive à escolha do local (PERIÓDICO..., 1853, p. 5). Todavia, a despeito do sucesso, e mesmo que fossem ocasiões aguardadas com ansiedade por uma parte cada vez maior da população, não se conseguia manter com regularidade a promoção de eventos náuticos.

Depois de quase dois anos sem regatas, nova expectativa se gestou em 1855. 0 desejo comunicado nos jornais era de organizar um evento acessível a todos, a ser encerrado com "um baile popular e um grande fogo de artifício que será queimado no mar" (CORREIO MERCANTIL, 1855b, p. 1). A promoção não seria de um clube, mas sim de um grupo não formal que tinha como um dos líderes o oficial de marinha Theotonio Meirelles da Silva ${ }^{11}$ (CORREIO MERCANTIL, 1855c, p. 2). A iniciativa contou com grande apoio dos poderes públicos, inclusive da Armada e do Imperador.

Esse evento parece ter reacendido a chama do remo na cidade. Na sequência, foram promovidos vários desafios entre proprietários de embarcações. Pelo menos um desses casos, uma disputa entre a brasileira S. Jorge e a inglesa Albion, realizada no Saco da Raposa (Ponta do Caju), ganhou ares de uma regata maior. Aparentemente, inclusive, foi criada uma agremiação, cujo secretário era Thomaz Rocha, da qual não conseguimos mais informações ${ }^{12}$ (CORREIO MERCANTIL, 1855d, p. 4).

Em junho de 1856, frente ao aumento do interesse pelas regatas - de brasileiros, portugueses e ingleses, de civis e militares da Armada -, uma reunião foi organizada no Hotel Pharoux para discutir temas como o melhor local para as provas, estratégias para conseguir recursos para premiações e despesas operacionais, regras a serem adotadas (CORREIO DA TARDE, 1856, p. 3). Ao fim, a despeito das boas intenções, nem sequer um evento foi realizado.

Na transição dos anos 1850/1860, referências à modalidade somente aparecem nos jornais para ironizar algum problema urbano: "Convida-se o fiscal de S. Domingos de Niterói para assistir à regata que deve ter lugar no domingo, na lagoa da rua Fresca, produzida por uma cachoeira de águas pútridas que todos os dias, depois das 10 horas, correm de uma casa [...]" (DIÁRIO..., 1861, p. 2).

Assim como o turfe, ainda tardaria alguns anos para o remo se consolidar.

\section{UM PERÍODO DE RECESSO (1856-1868)}

Entre os anos de 1856 e 1868, poucos eventos esportivos foram promovidos no município neutro da Corte $^{13}$. Em 1858, algumas corridas de cavalos foram realizadas no Hippodromo (também chamado de Torneios Romanos), estabelecimento localizado no Campo da Aclamação (Campo de Santana) (CORREIO MERCANTIL, 1858, p. 3), uma espécie de circo no qual se apresentavam espetáculos diversos, inclusive de ginástica e mesmo touradas

\footnotetext{
11 Esse militar se tornou um dos mais profícuos historiadores militares do século XIX. 12 Pelo teor da notícia, talvez se trate mesmo da antiga Sociedade Regata que seguia em funcionamento.

13 Com o Ato Adicional de 1834, que promoveu importantes modificações na Constituição de 1824, o Rio de Janeiro passou a ser designado como município neutro, passando a contar com uma Câmara própria e separada da Província do Rio de Janeiro. Essa foi uma mudança importante no tocante à construção de uma condição de centralidade para a capital, deixando claro sua forte relação com o poder monárquico, bem como sua situação especial no cenário nacional.
} 
(CORREIO DA TARDE, 1858, p. 3). Como observou criticamente um cronista que identificava as diferenças: "O que se segue é o que Sr. Barboglio (o proprietário) fez de alguma maneira um imbróglio, porque torneio não é hipódromo" (DIÁRIO..., 1858b, p. 1).

Em dezembro de 1861, surgiu a notícia de que havia interessados em de novo promover corridas de cavalos na cidade. Com o título de "Jockey Club" (CORREIO MERCANTIL, 1861e, p. 3), convocaram-se os interessados em se inscrever em páreos que seriam realizados na Praia Vermelha: "Entre vivas e hurras e ante um imenso concurso de espectadores (apesar [...] da corrida ter sido feita quase em segredo), correram os Srs. amadores, fica entendido que cada um com seu cavalo, os oito páreos do programa" (A SEMANA..., 1861, p. 3).

Apesar do sucesso, houve muita improvisação e desorganização. As raias eram inadequadas, as arquibancadas mal montadas chegaram a cair, o programa era pouco preciso, os parâmetros técnicos foram deficientes (CORREIO DA TARDE, 1861, p. 3). A Semana Ilustrada, sempre atenta e crítica, ironizou o evento: "Estamos em plena quadra de corridas tudo corre. [...] Correm cavalos montados pelos membros do Jockey-Club, alguns dos quais, não obstante serem corredores, saíram muito corridos por decepções" (A SEMANA..., 1861, p. 2).

Algumas edições depois, no mesmo periódico, publicou-se uma charge de Henrique Fleiuss, um dos mais profícuos desenhistas do século XIX, comparando o mau desempenho dos amadores com a boa performance de amazonas que atuavam no circo:

Figura 1 - Charge

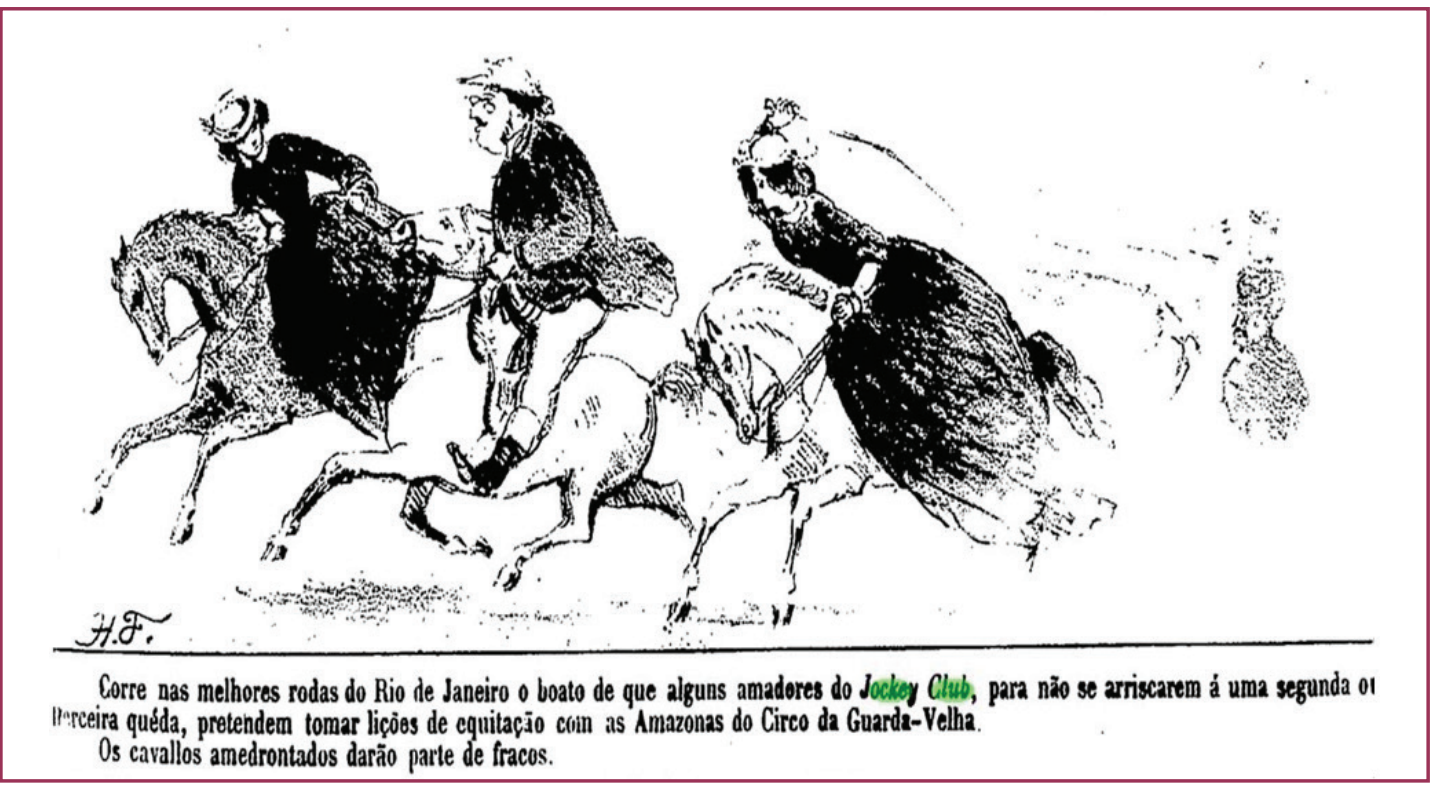

Fonte: A Semana..., 1861, p. 5

Cercados de críticas, o grupo não promoveu mais corridas, ainda que, em 1862, nova expectativa tenha se gerado: "Foi de novo organizado o Jockey Club: informam-nos que em breve haverá corrida na Praia Vermelha" (CORREIO MERCANTIL, 1862b, p. 2). Uma vez mais, tudo não passou de promessas.

Foi somente em 1868 que se deu uma iniciativa que no futuro seria responsável pela consolidação do turfe na capital: "Teve lugar ontem, na sala da Sociedade Auxiliadora da Indústria Nacional, uma reunião em que foi fundado um Jockey Club, com o fim de dar corridas 
de cavalos no Prado Fluminense" (DIÁRIO DO RIO DE JANEIRO, 1868, p. 1). A entidade que acolheu a cerimônia de criação da nova agremiação turfística:

Longe de ser uma associação de classe, [...] foi criada no espírito da llustração e era, como tantas outras sociedades da época, uma comunidade que se propunha ser científica, mas que congregava no mesmo espaço cientistas, letrados, políticos e homens ligados ao mundo dos negócios (BARRETO, 2008, p. 3).

Integravam a diretoria do novo clube importantes personagens do Império, como o já citado Marianno Procópio Ferreira Lage (presidente), o negociante e proprietário de terras Henrique José Teixeira ( $1^{\circ}$ secretário), o comerciante Felisberto C. Paes Leme $\left(2^{\circ}\right.$ secretário), José Dias Delgado de Carvalho (diretor), membro de uma família tradicional da nobreza brasileira, e Eduardo Augusto Pacheco (tesoureiro), proprietário de terras que se tornou um dos primeiros interessados na preservação da memória da modalidade. Estava próximo o fim do interregno das corridas de cavalos.

O remo passou por um processo similar ao do turfe. Em 1861, houve uma tentativa de retomar as regatas, a promoção de sete páreos nos quais tomaram parte amadores civis e militares (CORREIO MERCANTIL, 14 set. 1861, p. 3). Não havia uma agremiação organizando o evento, nem se exigia a filiação a qualquer clube, as inscrições foram individuais.

No dia do evento, um verdadeiro frenesi tomou conta do litoral, empolgando um jornalista: "A afluência que houve, 0 interesse que despertou a regata de Botafogo [...] faz esperar que os desse gênero se repitam, porque as regatas reúnem as duas condições recomendadas pelo poeta latino utile et dulce" (CORREIO MERCANTIL, 1861a, p. 1).

Nesse mesmo ano, surge a notícia de que estava a se organizar um novo clube marítimo (CORREIO MERCANTIL, 1861c, p. 1). Na divulgação de um evento náutico promovido por esse grupo, do qual não temos mais informações, explicitamente se afirmou: "Atendendo à conveniência do público, a regata será feita paralelamente à praia, [...] de modo a que os espectadores não percam um só dos incidentes da luta" (CORREIO MERCANTIL, 1861d, p. 4). Assumidamente a assistência passou a ser uma preocupação denotada.

A expectativa de que fosse grande 0 afluxo de público gerou até mesmo uma intervenção policial no sentido de organizar o estacionamento de carros que chegariam ao evento. Houve também a oferta de espaços alternativos para acolher os interessados: "Os espectadores da regata têm a sua disposição o melhor ponto para vê-la, subindo a estrada que do fim da rua do Olinda vai ter ao Mundo Novo [...]. Podem ali acomodar-se milhares de pessoas, que gozarão de melhor vista do que de qualquer casa da praia" (DIÁRIO..., 1861b, p. 3).

Uma vez mais, a despeito do sucesso, não se conseguia dar continuidade aos eventos náuticos. Em 1862, quando se anunciou a criação da Sociedade Passeio Marítimo e Regata (DIÁRIO..., 1862, p. 1), de novo houve dificuldades para organizar os páreos. Um cronista diagnosticou:

Entretanto já se fala de uma nova regata; temos certeza e quase aliançamos que só terá lugar desta data a três anos; não importa: se o melhor da festa é esperar por ela, esperaremos com o firme propósito de desesperarmos antes de chegarmos ao $2^{\circ}$ mês. Institui-se aqui uma sociedade, um clube, no $1^{\circ}, 2^{\circ}$ e $3^{\circ}$ mês tudo corre maravilhosamente bem; [...]; no $4^{\circ}$ mês baixa a temperatura [...]; no $5^{\circ}$ mês poucas pessoas vão às partidas [...] (CORREIO MERCANTIL, 1862a, p. 3) (14 $^{14}$.

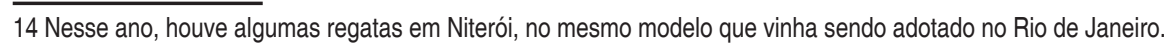


Como no turfe, foi também a partir da segunda metade dos anos 1860 que esse quadro começou a mudar, com a criação do Club de Regatas, que semearia o caminho para muitas agremiações, antecipando a fundação do importante Club de Regatas Guanabarense (1874).

Vale ainda fazer referência a uma modalidade que não logrou grande popularidade, com a qual os britânicos estabelecidos na cidade estavam envolvidos desde a primeira metade do século XIX: o cricket (MELO, 2014).

Conseguimos mais informações sobre a prática a partir de 1865, quando foi lançado o The Anglo-Brazilian Times: Political Litterary and Comercial, editado pelo irlandês William Scully, um dos líderes da colônia britânica na capital estabelecida ${ }^{15}$. Logo nos primeiros exemplares do periódico, encontramos uma notícia sobre o British Cricket Club. Comenta-se que a agremiação recebera uma doação de material esportivo, o que permitiria o "ressurgimento do esplêndido jogo durante o inverno" (THE ANGLO-BRAZILIAN..., 1865a, p. 1). Concluiu-se a notícia com uma conclamação: "Desejamos toda prosperidade para o novo clube e esperamos que ressurja como uma Fênix das cinzas da antiga agremiação". Isto é, mais do que a prática espontânea, há indícios de que existiu um clube de cricket no Rio de Janeiro antes de 1865, sobre o qual não conseguimos até o momento mais informações.

Em maio de 1865, um anúncio chama a atenção, a convocação do time principal do já denominado Rio British Cricket Club para enfrentar o Artisans Amateur Cricket Club (THE ANGLO-BRAZILIAN..., 1865b, p. 4). Havia, portanto, outra agremiação na cidade, sobre o qual também não temos muitas informações. De toda forma, há indícios de boa movimentação ao redor da modalidade. Além dos encontros entre os dois clubes, eram comuns os jogos desses contra equipes de navios ingleses que chegavam ou estavam ancorados na baía de Guanabara, como o que foi realizado com os oficiais do H. M. S. Narcisus (THE ANGLOBRAZILIAN..., 1865c, p. 4). Houve ainda partidas entre as embarcações e entre combinados de civis e militares.

Os eventos eram realizados em um ground que se localizava no Campo de Santana, importante espaço de entretenimento da cidade (SEGAWA, 1996). Os times eram formados exclusivamente por ingleses, que também compunham a maioria do público. Só eventualmente havia uma assistência mais ampla, atraída pela curiosidade. Na verdade, sequer se encontram anúncios das partidas nos periódicos de grande circulação. Não parecia mesmo ser desejo dos britânicos contar com uma plateia maior; era uma ocasião para que se encontrassem ao redor de uma prática cultural típica dos seus países de origem ${ }^{16}$.

Distintamente do que ocorreu com as duas outras modalidades, que começaram a ressurgir no final dos anos 1860, a prática do cricket entrou em declínio. Em 1868, o The AngloBrazilian Times publicou uma carta de um recém-chegado na qual demonstrou surpresa com o que considerava imobilidade dos seus patrícios. Não aceitava que o British Cricket estivesse inativo, e que não houvesse nenhuma outra agremiação esportiva por eles dinamizada: "Estou assustado por saber que os ingleses do Rio não têm clubes de turfe ou remo" (THE ANGLOBRAZILIAN..., 1868a, p. 3). 0 autor observava que esse era um hábito comum pelo mundo onde houvesse estabelecido um grupo de britânicos, que aprendiam desde cedo a amar o esporte.

15 Para mais informações sobre o periódico e seu atuante editor, ver: <http://www.irlandeses.org/dilab_scullyw.html>. Acesso em: 19 jun. 2014.

16 Para uma discussão sobre as peculiaridades dos britânicos estabelecidos no Brasil, ver Freyre (1977). 
Alguns meses depois, outra carta observou o mesmo, mais claramente detectando a inatividade do British Club. $\mathrm{O}$ autor sugeria ser urgente que se reabilitasse o ground do Campo de Santana, conclamando que fosse fundada uma nova agremiação, já que a anterior "aparentemente desapareceu" (THE ANGLO-BRAZILIAN..., 1868b, p. 3). 0 editor fez coro a essa reivindicação, criticando o desinteresse pelo esporte: "Esperamos melhores coisas de nossos jovens ingleses do que 0 abandono de um jogo nacional que tem seguido os ingleses ao redor do mundo" (THE ANGLO-BRAZILIAN..., 1868c, p. 3). Foi somente na década de 1870 que de novo floresceu o cricket na capital.

\section{CONCLUSÃO}

Os anos 1850 foram um período de grande prosperidade para o país, um divisor de águas na história brasileira, um momento de grandes transformações e de consolidação do Estado (CARVALHO, 2012, CHALHOUB, 2012). Na capital do Império, sentiram-se claramente impactos dessas mudanças, inclusive iniciativas relacionadas à melhor organização dos serviços públicos: saneamento, distribuição de água, iluminação, sistema de saúde, estrutura de transportes (CHALHOUB, 2012). O Rio de Janeiro definitivamente se consolidou como a mais importante cidade do Brasil, principal centro de entrada dos mais diferentes produtos e pessoas, das mais diversas nacionalidades, bem como um foco irradiador de modas e costumes (SCHWARCZ, 1998).

Nesse cenário, gestou-se uma dinâmica pública mais intensa, manifesta, inclusive, na melhor estruturação de um mercado ao redor das diversões. Na capital da nova nação que se consolidava, a sociedade civil se organizava e se fazia reconhecer também no âmbito do entretenimento, que rapidamente se ampliava, ajudando a reforçar e expor as contradições e ambiguidades que cercavam as iniciativas de adoção de novos parâmetros civilizatórios. Foi nesse contexto que ocorreram as primeiras e mais organizadas experiências esportivas na cidade.

A década seguinte não seria tão alvissareira por diversas razões. Uma nova geração passou mais intensamente a explicitar suas discordâncias com o governo de Pedro II, o que se acentuou com a melhor organização de iniciativas republicanas, que se fortaleceram em função dos desdobramentos da Guerra do Paraguai, um dos episódios-chave da história brasileira, finda a qual se pôde perceber tanto o auge do Império quanto o início de seu fim.

Esse conflito teve significativo impacto no cotidiano da capital. Do ponto de vista simbólico, se foi de grande importância para o forjar de uma identidade nacional, instituiu uma apreensão nas cidades, que se refletiu em certo arrefecimento da vida festiva. Além do clima de preocupação, sentiam-se os desdobramentos financeiros da guerra, ampliando as dificuldades econômicas de uma crise que já vinha se delineando, por problemas no cenário internacional, nos anos de 1861-1864 (BETHELL, 2012, CARVALHO, 2012). Mais ainda, as sucessivas epidemias, entre as quais de febre amarela e cólera, assustavam a população, contribuindo para afastá-la do cenário público (CHALHOUB, 2006).

Nesse momento, eram ainda embrionárias as iniciativas esportivas. Não se dominava plenamente o complexo funcionamento e equacionamento econômico necessário para a manutenção das atividades. Deve-se considerar também que não era tão grande o público consumidor. Segundo o primeiro censo oficial realizado (1872), havia 274.972 habitantes no 
Rio de Janeiro, sendo 228.743 na cidade (o restante vivia nas áreas rurais); desses, 191.176 eram livres.

Deve-se, portanto, entender esse período de transição da conformação do campo esportivo a partir de uma dupla dimensão. Internamente, os protagonistas ainda não conseguiam gerenciar adequadamente as atividades das agremiações, inclusive não compreendendo a necessidade de adotar um modelo que, mesmo mantendo mecanismos de distinção, não afastasse e mesmo atraísse o grande público, sem o qual não seria possível viabilizar a manutenção da prática. Externamente, havia que se contar com determinadas condições contextuais, inclusive do ponto de vista de consolidação de um mercado consumidor, notadamente com o melhor delineamento de um estrato socioeconomicamente intermediário.

O caso do cricket é, contudo, distinto. Como a modalidade não logrou popularidade entre os nacionais, ficando restrita aos ligados à colônia britânica, a continuidade de sua prática sempre dependeu mais da ação de algumas lideranças que, quando deixavam a cidade - havia muito trânsito entre os ingleses - acabavam por desanimar a cena.

Havia mesmo uma incompreensão que cercava a modalidade. Mascarenhas (2008) lembra que, quando o Rio British Cricket Club pediu à Câmara Municipal autorização para construir o ground no Campo de Santana, o poder público sequer entendia do que se tratava a prática.

Nos outros dois casos, do turfe e do remo, a articulação das duas dimensões citadas, aspectos internos do campo e externo-contextuais, ajuda a entender o porquê de o campo esportivo dar passos mais seguros no Rio de Janeiro a partir do final dos anos 1860.

De toda forma, parece-me importante chamar a atenção para o fato de que, naquele momento, ainda que com muitos limites, já havia certas dimensões que melhor se delineariam no decorrer do século XIX: conflitos entre adeptos do turfe e do remo, relacionados a datas de eventos, dinâmica de funcionamento de clubes e competições, sentidos e significados da prática; gestação de um mercado ao redor das modalidades; debates sobre o perfil adequado do público e dos praticantes. Trata-se de temas que serão fulcrais na definitiva conformação do campo esportivo no Rio de Janeiro.

\section{REFERÊNCIAS}

A SEMANA ILUSTRADA, Rio de Janeiro, n. 54, 1861, p. 3.

ALMANAK LAEMMERT, Rio de Janeiro, 1854, p. 344.

BARRETO, Patrícia Regina Corrêa. Sociedade Auxiliadora da Indústria Nacional: Oficina de Homens. In: ENCONTRO DE HISTÓRIA DA ANPUH/RIO, 13., 2008, Rio de Janeiro. Anais... Rio de Janeiro: Anpuh/Rio, 2008. Disponível em: < http://www.encontro2008.ri.anpuh.org/resources/ content/anais/1212685654_ARQUIVO_ARTIGOREVISADO.pdf>. Acesso em: 27 ago. 2014.

BETHELL, Leslie. O Brasil no mundo. In: CARVALHO, José Murilo (Coord.). História do Brasil Nação (1808-2010). Rio de Janeiro: Objetiva, 2012. v. 2: A construção nacional (1830-1889). p. 131-178.

BOURDIEU, Pierre. Como é possível ser esportivo? In: BOURDIEU, Pierre. Questões de sociologia. Rio de Janeiro: Marco Zero. 1983. p.136-163. 
CARVALHO, José Murilo. A vida política. In: CARVALHO, José Murilo (Coord.). História do Brasil Nação (1808-2010). Rio de Janeiro: Objetiva, 2012. v. 2: A construção nacional (18301889). p. 83-130.

CHALHOUB, Sidney. Cidade febril: cortiços e epidemias na corte imperial. São Paulo: Companhia das Letras, 2006.

CHALHOUB, Sidney. População e sociedade. In: CARVALHO, José Murilo (Coord.). História do Brasil Nação (1808-2010). Rio de Janeiro: Objetiva, 2012. v. 2: A construção nacional (18301889). p. 37-82.

CORREIO DA TARDE, Rio de Janeiro, 22 abr. 1856, p. 3.

CORREIO DA TARDE, Rio de Janeiro, 2 nov. 1858, p. 3.

CORREIO DA TARDE, Rio de Janeiro, 16 dez. 1861, p. 3.

CORREIO MERCANTIL, Rio de Janeiro, 10 ago. 1852a, p. 3.

CORREIO MERCANTIL, Rio de Janeiro, 19 out. 1852b, p. 2.

CORREIO MERCANTIL, Rio de Janeiro, 21 out. 1852c, p. 2.

CORREIO MERCANTIL, Rio de Janeiro, 22 out. 1852d, p. 1.

CORREIO MERCANTIL, Rio de Janeiro, 30 out. 1852e, p. 2.

CORREIO MERCANTIL, Rio de Janeiro, 11 dez. 1853, p. 1.

CORREIO MERCANTIL, Rio de Janeiro, 18 fev. 1855a, p. 2.

CORREIO MERCANTIL, Rio de Janeiro, 21 abr. 1855b, p. 1.

CORREIO MERCANTIL, Rio de Janeiro, 3 maio 1855c, p. 2.

CORREIO MERCANTIL, Rio de Janeiro, 28 jun. 1855d, p. 4.

CORREIO MERCANTIL, Rio de Janeiro, 12 maio 1856a, p 4.

CORREIO MERCANTIL, Rio de Janeiro, 24 jul. 1856b, p. 1.

CORREIO MERCANTIL, Rio de Janeiro, 29 set. 1858, p. 3.

CORREIO MERCANTIL, Rio de Janeiro, 14 set. 1861a, p. 3.

CORREIO MERCANTIL, Rio de Janeiro, 1 out. 1861b, p. 1.

CORREIO MERCANTIL, Rio de Janeiro, 4 out. 1861c, p. 1.

CORREIO MERCANTIL, Rio de Janeiro, 12 out. 1861d, p. 4.

CORREIO MERCANTIL, Rio de Janeiro, 7 dez. 1861e, p. 3.

CORREIO MERCANTIL, Rio de Janeiro, 18 jul. 1862a, p. 3.

CORREIO MERCANTIL, Rio de Janeiro, 6 set. 1862b, p. 2. 
DIÁRIO DO RIO DE JANEIRO, Rio de Janeiro, 22 nov. 1853, p. 2.

DIÁRIO DO RIO DE JANEIRO, Rio de Janeiro, 13 jul. 1855, p. 4.

DIÁRIO DO RIO DE JANEIRO, Rio de Janeiro, 2 jun. 1856a, p. 1.

DIÁRIO DO RIO DE JANEIRO, Rio de Janeiro, 28 set. 1856b, p. 4.

DIÁRIO DO RIO DE JANEIRO, Rio de Janeiro, 17 jan. 1857, p. 2.

DIÁRIO DO RIO DE JANEIRO, Rio de Janeiro, 12 maio 1858a, p. 2.

DIÁRIO DO RIO DE JANEIRO, Rio de Janeiro, 26 set. 1858b, p. 1.

DIÁRIO DO RIO DE JANEIRO, Rio de Janeiro, 7 abr. 1861a, p. 2.

DIÁRIO DO RIO DE JANEIRO, Rio de Janeiro, 1 nov. 1861b, p. 3.

DIÁRIO DO RIO DE JANEIRO, Rio de Janeiro, 10 jul. 1862, p. 1.

DIÁRIO DO RIO DE JANEIRO, Rio de Janeiro, 17 jul. 1868, p. 1.

FREYRE, Gilberto. Ingleses no Brasil. 2. ed. Rio de Janeiro: José Olympio, 1977.

O GRITO NACIONAL, Rio de Janeiro, 28 mar. 1852, p. 1.

JORNAL DAS SENHORAS, Rio de Janeiro, 14 nov. 1852, p. 159.

JORNAL DO COMÉRCIO, Rio de Janeiro, 7 nov. 1852, p. 1.

LUCA, Tânia Regina de. História dos, nos e por meio dos periódicos. In: PINSKY, Carla

Bassanezi (Org.). Fontes históricas. São Paulo: Contexto, 2005. p. 111-153.

LUCENA, Ricardo. 0 esporte na cidade. São Paulo: Autores Associados, 2001.

MASCARENHAS, Gilmar. Construindo a cidade moderna: A introdução dos esportes na vida urbana do Rio de Janeiro. Estudos Históricos, Rio de Janeiro, v. 13, n. 23, p. 17-39, 1999.

MASCARENHAS, Gilmar. Primórdios do futebol na Cidade do Rio de Janeiro. Revista do Instituto Histórico e Geográfico Brasileiro, Rio de Janeiro, v. 69, n. 439, p. 101-112, abr.jjun. 2008.

MELO, Victor Andrade de. Cidade Sportiva: primórdios do esporte no Rio de Janeiro. Rio de Janeiro: Relume Dumará/Faperj, 2001.

MELO, Victor Andrade de. "Temos apaixonados para o mar e para a terra": representações do esporte nos folhetins (Rio de Janeiro; 1851-1855). Revista Brasileira de Educação Física e Esporte, São Paulo, v. 27, n. 4, p. 553-566, dez. 2013.

MELO, Victor Andrade de. Antes do club: as primeiras experiências esportivas na capital do Império (1825-1851). Projeto História, São Paulo, v. 49, p. 197-236, abr. 2014.

MELO, Victor Andrade de, PERES, Fabio de Faria. A gymnastica nos tempos do Império. Rio de Janeiro: 7 Letras/Faperj, 2014.

PERIÓDICO DOS POBRES, Rio de Janeiro, 4 nov. 1852, p. 5. 
PERIÓDICO DOS POBRES, Rio de Janeiro, 10 dez. 1853, p. 5.

SCHETINO, André Maia. Pedalando na modernidade: a bicicleta e o ciclismo na transição do século XIX para o XX. Rio de Janeiro: Apicuri, 2008.

SCHWARCZ, Lilia Moritz. As barbas do Imperador. São Paulo: Companhia das Letras, 1998.

SEGAWA, Hugo. Ao amor do público: jardins no Brasil. São Paulo: Studio Nobel/Fapesp, 1996.

THE ANGLO-BRAZILIAN TIMES, Rio de Janeiro, 24 mar. 1865a, p. 1.

THE ANGLO-BRAZILIAN TIMES, Rio de Janeiro, 24 maio 1865b, p. 4

THE ANGLO-BRAZILIAN TIMES, Rio de Janeiro, 8 jun. 1865c, p. 4.

THE ANGLO-BRAZILIAN TIMES, Rio de Janeiro, 8 jul. 1868a, p. 3.

THE ANGLO-BRAZILIAN TIMES, Rio de Janeiro, 21 dez. 1868b, p. 3.

THE ANGLO-BRAZILIAN TIMES, Rio de Janeiro, 23 dez. 1868c, p. 3. 